\title{
Inorganic nitrogen wet deposition: Evidence from the North-South Transect of Eastern China
}

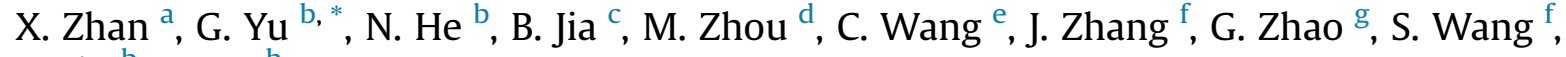 \\ Y. Liu ${ }^{\text {b }}$, J. Yan ${ }^{\mathrm{h}}$ \\ a Institute of Soil and Water Conservation, Northwest A\&F University, Yangling 712100, Shaanxi, China \\ ${ }^{b}$ Synthesis Research Center of Chinese Ecosystem Research Network, Key Laboratory of Ecosystem Network Observation and Modeling, Institute of \\ Geographic Sciences and Natural Resources Research, Chinese Academy of Sciences, Beijing 100101, China \\ ${ }^{\mathrm{c}}$ Institute of Botany, Chinese Academy of Sciences, Beijing 100093, China \\ d College of Ecology and Environmental Science, Inner Mongolia Agricultural University, Hohhot 010019, China \\ e College of Forestry, Northeast Forestry University, Harbin 150040, China \\ ${ }^{\mathrm{f}}$ Institute of Applied Ecology, Chinese Academy of Sciences, Shenyang 110016, China \\ ${ }^{\mathrm{g}}$ Institute of Forest Ecology Environment and Protection, Chinese Academy of Forestry, Beijing 100091, China \\ ${ }^{\mathrm{h}}$ South China Botany Garden, Chinese Academy of Sciences, Guangzhou 510650, China
}

\section{A R T I C L E I N F O}

\section{Article history:}

Received 27 October 2014

Received in revised form

6 March 2015

Accepted 8 March 2015

Available online 18 April 2015

\section{Keywords:}

Nitrogen deposition

Critical load

Anthropogenic activity

Forest ecosystem

Eastern China

\begin{abstract}
A B S T R A C T
We examined the spatio-temporal variation of dissolved inorganic nitrogen (DIN) deposition in eight typical forest ecosystems of Eastern China for three consecutive years. DIN deposition exhibited an increasing gradient from north to south, with $\mathrm{N}-\mathrm{NH}_{4}^{+}$as the predominant contributor. DIN deposition in precipitation changed after interaction with the forest canopy, and serious ecological perturbations are expected in this region. DIN deposition presented seasonal fluctuations, which might be ascribed to agricultural activity, fossil-fuel combustion and environmental factors (i.e., wind direction, soil temperature). Notably, $\mathrm{N}$ fertilizer use $\left(\mathrm{F}_{\mathrm{N}}\right)$, energy consumption $(\mathrm{E})$, and precipitation $(\mathrm{P})$ jointly explained $84.3 \%$ of the spatial variation in DIN deposition, of which $\mathrm{F}_{\mathrm{N}}(27.2 \%)$ was the most important, followed by $\mathrm{E}$ (24.8\%), and finally $\mathrm{P}$ (9.3\%). The findings demonstrate that DIN deposition is regulated by precipitation mainly via anthropogenic $\mathrm{N}$ emissions, and this analysis provides decision-makers a novel view for $\mathrm{N}$ pollution abatement.
\end{abstract}

() 2015 Elsevier Ltd. All rights reserved.

\section{Introduction}

Atmospheric nitrogen $(\mathrm{N})$ deposition has increased sharply due to the rapid increase in reactive $\mathrm{N}$ resulting from industrialization and intensive agricultural activities over the last century (Galloway et al., 2008). Excessive $\mathrm{N}$ deposition has resulted in serious environmental issues globally, including global warming (Churkina et al., 2009), loss of biodiversity (Bobbink et al., 2010), surface water acidification (Bouwman et al., 2002), and risks to human health (Richter et al., 2005).

Although forests are commonly considered to be $\mathrm{N}$ deficient,

\footnotetext{
* Corresponding author. Institute of Geographic Sciences and Natural Resources Research, Chinese Academy of Sciences 11A, Datun Road Chaoyang District, Beijing 100101, China.

E-mail address: yugr@igsnrr.ac.cn (G. Yu).
}

and there is no direct anthropogenic nitrogen input like fertilizer to unmanaged forests (Thomas et al., 2010), recent studies have confirmed that $\mathrm{N}$ deposition in forests has reached unprecedented levels because of anthropogenic activities, and the "N saturation" hypothesis was then brought up (Nave et al., 2009; Sutton et al., 2011). Thus, quantifying $\mathrm{N}$ deposition in forests has been a crucial topic in global biogeochemical research. Consequently, several research programmes have been initialed to study atmospheric $\mathrm{N}$ deposition in forests, such as the large-scale European NITREX (Nitrogen saturation experiment), SFONE (Swedish Forest Optimum Nutrition Experiments), and EANET (Acid deposition monitoring network in East Asia). These programmes found that " $\mathrm{N}$ saturation" appeared in many forests, i.e., in Poland and many parts of Europe (Fischer et al., 2007; Walna and Kurzyca, 2007). However, researches on $\mathrm{N}$ deposition in China have primarily focused on heavily polluted regions, and only few measurements have been conducted in forests (Fang et al., 2011; Zhao et al., 2009). Concerns 
over $\mathrm{N}$ deposition in Chinese forests remain in the initial stage, and little is known about the current $\mathrm{N}$ deposition and its drivers using observed data on the regional scale (Chen and Mulder, 2007; Yu et al., 2011).

Located in the heavily forested area, the North-South Transect of Eastern China (NSTEC) provides an ideal platform for studying dissolved inorganic $\mathrm{N}$ (DIN, including $\mathrm{N}-\mathrm{NO}_{3}^{-}$and $\mathrm{N}-\mathrm{NH}_{4}^{+}$) deposition in Chinese forest ecosystems. In order to fill the gap in the knowledge of $\mathrm{N}$ deposition, a study in the NSTEC was undertaken. In this study, integrated DIN deposition data were measured continuously by the ion-exchange resin (IER) technique for three years, and data on wind direction, precipitation, $\mathrm{N}$ fertilizer use and energy consumption were used to present a more comprehensive assessment of DIN deposition in typical forest ecosystems. The primary purposes of this study were to investigate the spatiotemporal variation of DIN deposition, and the associated driving forces. The outcomes of our investigation may be of value to planners and decision-makers in their efforts to evaluate the effects of consequent $\mathrm{N}$ deposition on forest ecosystems and then to curb $\mathrm{N}$ emissions within the study region.

\section{Materials and methods}

\subsection{Study site}

The NSTEC extends from Hainan Island to China's northern border, with a spatial distance of more than $3700 \mathrm{~km}$, ranging from $108^{\circ} \mathrm{E}$ to $118^{\circ} \mathrm{E}$ for latitude below $40^{\circ} \mathrm{N}$ and from $118^{\circ} \mathrm{E}$ to $128^{\circ} \mathrm{E}$ for latitude above $40^{\circ} \mathrm{N}$ (Fig. 1). Due to the influence of the East Asian monsoon, the climate of the NSTEC displays obvious latitudinal gradients for temperature and precipitation, and the great spatial variation in climate is the primary driver for the diverse distribution of forest ecosystems within the transect (Peng et al., 2002).

In order to guarantee the smooth development of our observations (such as field sampling and sample storage), only sites with staff and basic experiment facilities were chosen. Thus, eight monitoring sites were selected: Huzhong (HZ), Genhe (GH), Mao'ershan (MES), Changbaishan (CBS), Daganshan (DGS), Huitong (HT), Qianyanzhou (QYZ), and Dinghushan (DHS). HZ, GH, MES, and $\mathrm{CBS}$ reside in the northern part of the transect, and the others belong to the southern part of the transect. $\mathrm{HZ}$ and $\mathrm{GH}$ are located in remote mountain areas that are far away from cities, with

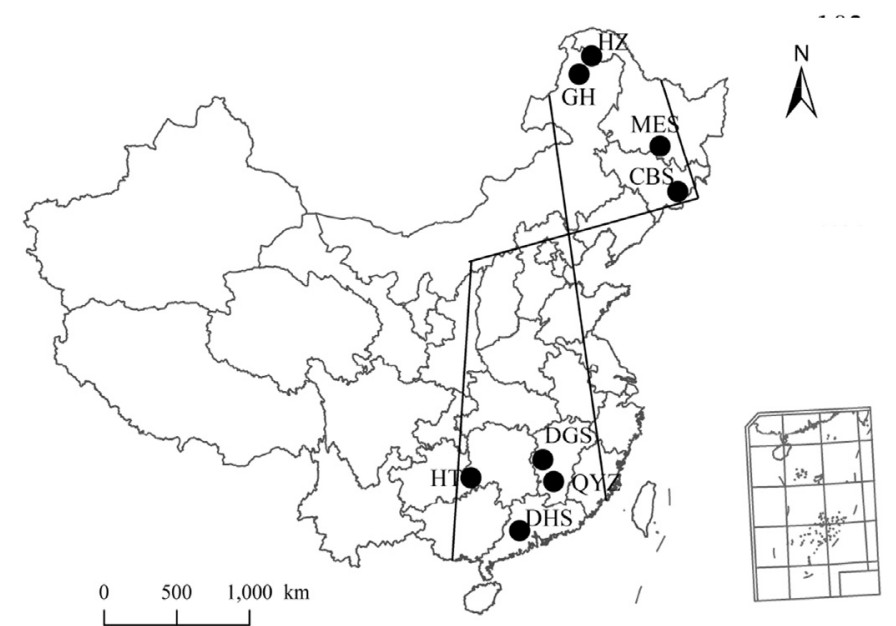

Fig. 1. Locations of eight monitoring sites (black dots). The region between the two lines represents the area of the North-South Transect of Eastern China (NSTEC). forestlands of 147, $000 \mathrm{ha}^{-1}$ and 553, $000 \mathrm{ha}^{-1}$, respectively. MES and CBS are surrounded by farmlands with spring wheat. DGS lies in Fenyi Town, and is approximately $30 \mathrm{~km}$ away from the center of Yichun City. HT and QYZ are located at forest ecological experiment stations, in Guangping Town, and in Taihe Town, respectively; they are surrounded by dry farmlands with paddy fields. Paddy fields, dry farmlands and factories surround the DHS study site; Guangzhou city, a typical economic area, is located $64 \mathrm{~km}$ east of DHS. Details for all of the sites are listed in Table 1, and geographical distribution of the sites is mapped in Fig. 1.

\subsection{Sampling and chemical analysis}

In this study, IER columns were used to evaluate DIN deposition in throughfall (throughfall DIN deposition) and in precipitation (bulk DIN deposition) in forest ecosystems. Information about the design of the IER columns was illustrated in detail in a previous study (Sheng et al., 2013). The IER technique is superior to conventional methods (i.e., traditional rainfall collection), which are labor intensive and analytically expensive to implement on a broad scale (Fenn and Poth, 2004).

At each site, five IER columns were randomly placed under the canopy to measure throughfall DIN deposition, and five others were placed in an open area to collect bulk DIN deposition. Additionally, two IER columns with both ends sealed were installed to determine the background $\mathrm{N}$ in the ion resin (Fenn and Poth, 2004). Background $\mathrm{N}$ in the resin, although minimal, should be subtracted from the deposition data to determine the actual DIN deposition. All the IER columns were placed $1 \mathrm{~m}$ above the ground to avoid litter, debris, and other contaminants. From May 2008 to April 2011, the columns were retrieved monthly and new columns were installed, whereas observations at DGS were conducted monthly for two consecutive years (from May 2008 to April 2010) for a variety of reasons. Because of serious weather conditions, observations were conducted monthly only during the growing season (from May to October), whereas just one value for DIN deposition could be obtained during the nongrowing season (from November to April the following year) at $\mathrm{HZ}, \mathrm{GH}, \mathrm{MES}$ and $\mathrm{CBS}$. Ion-exchange resin will lose its potency in cold winter weather; therefore, a conventional rainfall collection method was conducted at the four sites during the nongrowing season.

At the end of each field sampling, the resin columns were unscrewed from the funnel assembly, sealed at both ends, and returned to the laboratory. We then performed preliminary laboratory tests with the resin columns that were preloaded with a simulated deposition solution to test the absorption efficiency of the mixed resins and the recovery efficiency of the preloaded resins. The results showed that the absorption efficiency was more than $99.0 \%$ for $\mathrm{N}-\mathrm{NO}_{3}^{-}$and $\mathrm{N}-\mathrm{NH}_{4}^{+}$, and the recovery efficiency was $90.3 \%-95.5 \%$ for $\mathrm{N}-\mathrm{NO}_{3}^{-}$and $90.9 \%-100.0 \%$ for $\mathrm{N}-\mathrm{NH}_{4}^{+}$after three $\mathrm{KCl}$ extractions. Therefore, the samples were mixed well and then filtered three

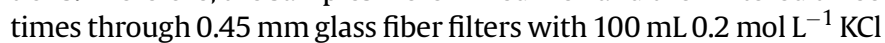
solutions before analysis. $\mathrm{N}-\mathrm{NO}_{3}^{-}$and $\mathrm{N}-\mathrm{NH}_{4}^{+}$in the extract was analyzed by following a standard procedure on a continuous flow analyzer (TRAACS 2000, Bran-Luebbe Inc., Germany).

\subsection{Calculation of DIN deposition}

Monthly DIN deposition (DINmon, kg-N ha ${ }^{-1}$ ) collected by the IER columns was calculated according to the following formula (Sheng et al., 2013):

$D I N_{\text {mon }}=C_{\mathrm{ex}} \times V_{\mathrm{ex}} / 100 A$

where Cex is $\mathrm{N}\left(\mathrm{N}-\mathrm{NO}_{3}^{-}\right.$and $\left.\mathrm{N}-\mathrm{NH}_{4}^{+}\right)$concentration $\left(\mathrm{mg}-\mathrm{N} \mathrm{L}^{-1}\right)$ 
Table 1

Site characteristics within the North-South Transect of Eastern China (NSTEC).

\begin{tabular}{|c|c|c|c|c|c|}
\hline Site & Long $\left(\mathrm{E}^{\circ}\right)$ & Lat $\left(\mathrm{N}^{\circ}\right)$ & $\operatorname{MAT}\left({ }^{\circ} \mathrm{C}\right)$ & MAP (mm) & Forest ecosystem \\
\hline $\mathrm{HZ}$ & 123.0 & 51.8 & -5.6 & 525.8 & Deciduous coniferous forest \\
\hline $\mathrm{GH}$ & 121.5 & 50.8 & -5.1 & 466.7 & Deciduous coniferous forest \\
\hline MES & 127.5 & 45.4 & 1.1 & 663.6 & Mixed conifer and broadleaved forest \\
\hline CBS & 128.1 & 42.4 & 3.0 & 714.1 & Broad-leaved Korean pine mixed forest \\
\hline DGS & 114.5 & 27.5 & 17.0 & 1633.7 & Evergreen broadleaved forest \\
\hline HT & 109.4 & 26.7 & 15.6 & 1393.6 & Evergreen coniferous forest \\
\hline QYZ & 115.1 & 26.1 & 17.1 & 1675.1 & Evergreen coniferous forest \\
\hline DHS & 112.5 & 23.2 & 22.1 & 1771.1 & Evergreen broadleaved forest \\
\hline
\end{tabular}

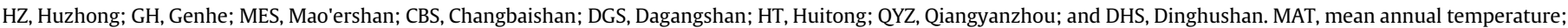
MAP, mean annual precipitation.

in the extract, Vex is volume of the extract (L), $A$ is area of funnel $\left(\mathrm{m}^{2}\right)$, and 100 is a unit conversion factor.

DIN deposition in winter (DINwin, $\mathrm{kg}^{-\mathrm{N}} \mathrm{ha}^{-1}$ ) was calculated by multiplying the amount of precipitation by the $\mathrm{N}$ concentration in winter (Yu et al., 2011):

$D I N_{\text {win }}=C_{\text {win }} \times P_{\text {win }} / 100$

where $C$ win is $\mathrm{N}\left(\mathrm{N}-\mathrm{NO}_{3}^{-}\right.$and $\left.\mathrm{N}-\mathrm{NH}_{4}^{+}\right)$concentration $\left(\mathrm{mg}-\mathrm{N} \mathrm{L}^{-1}\right)$ in winter, and Pwin is precipitation amount ( $\mathrm{mm}$ ) in winter.

\subsection{Data sources on meteorology and anthropogenic $N$ sources}

Meteorological data (including wind direction and precipitation) in the monitoring sites were continuously monitored using Milos 520 automatic weather stations, and could be obtained from Chinese Ecosystem Research Network (http://www.cerndata.ac.cn/ ). We used Near tool in the ArcGIS 10.0 Software to calculate and record the distance between each forest site and the nearest large city. The nearest large city (with more than 2 million inhabitants), includes the urban area, and its periphery cropland and wild land. Data on $\mathrm{N}$ fertilizer use (expressed as the volume of the effective component) and energy consumption (expressed as standard coal) in the nearest large city mainly derived from the governmental statistics year books and bulletins (National Bureau of Statistics of China, 2009-2011), which supplied the best available data for the quantification of anthropogenic $\mathrm{N}$ in China.

\subsection{Statistical analysis}

One-way analysis of variance (ANOVA) was adopted to test the differences in mean annual DIN deposition among different sampling sites and was followed by Fisher's least significant difference (LSD) comparisons when the differences were significant. Linear regression analysis or dynamic curve fit was used to analyze the relationships between throughfall DIN deposition and its drivers. By comparing the distribution of the scatter diagram and $\mathrm{R}^{2}$, we selected the better-fit functions that had a higher $\mathrm{R}^{2}$ value.

The effect of the distance between forest sites and the nearest large city on throughfall DIN deposition depends mainly on anthropogenic $\mathrm{N}$ sources ( $\mathrm{N}$ fertilizer use and energy consumption). Additionally, precipitation transports $\mathrm{N}$ emissions while anthropogenic $\mathrm{N}$ sources are released to the atmosphere. Hence, considering the combined effects of the drivers on throughfall DIN deposition, only $\mathrm{N}$ fertilizer use, energy consumption and precipitation were analyzed. To identify the relative effects and interactive effects of the above three factors on throughfall DIN deposition, we conducted a partial general linear model (GLM) using throughfall DIN deposition as dependent variable, and $\mathrm{N}$ fertilizer use, energy
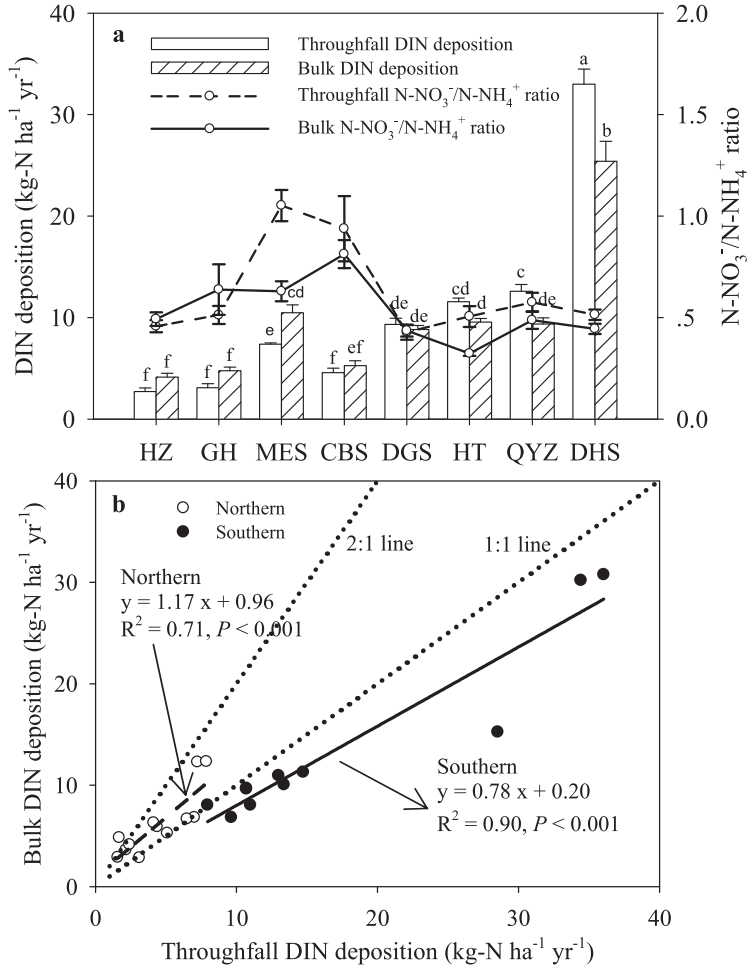

Fig. 2. (a) Comparison of mean annual dissolved inorganic nitrogen (DIN) deposition. Values are mean $\pm \operatorname{SE}(n=3)$, and different lowercase letters in each bar indicate significant differences in DIN deposition among forest ecosystems; (b) Relationship between bulk DIN deposition and throughfall DIN deposition.

consumption and precipitation as predictors. The partial regression divides the variation in response variable explained by several predictor variables into independent components (representing the independent effects of an individual explanatory variable when controlling effects of the other explanatory variables) and joint components (usually representing the collinearities between explanatory variables). The variation partitioning with three explanatory matrices leads to the identification of seven fractions in this study, i.e., independent effects of $\mathrm{N}$ fertilizer use, energy consumption, and precipitation; interactive effects of $\mathrm{N}$ fertilizer use and energy consumption, $\mathrm{N}$ fertilizer use and precipitation, energy consumption and precipitation, and the interactive effect of all variables. Further details about the method were given in Heikkinen et al. (2005).

Statistical significance was measured at the $95 \%$ confidence level unless otherwise stated. All the analyses were conducted by SPSS 16.0 statistical software (SPSS Inc., Chicago, IL, USA), and the graphs were performed by SimPlot 13.0 software. 


\section{Results and discussion}

\subsection{Spatial pattern of mean annual DIN deposition}

During the three-year observation period, yearly DIN deposition increased, but the differences were marginally significant (for throughfall DIN deposition, $\mathrm{F}=0.24, P=0.79$; for bulk DIN deposition, $\mathrm{F}=1.02, P=0.38$ ). Therefore, we did not elaborate on this. In our study, mean annual DIN deposition exhibited a remarkable spatial pattern, which increased from north to south. Mean annual throughfall DIN deposition was substantially greater in DHS than those in any other sites, and the trend was similar to that of mean annual bulk DIN deposition (Fig. 2a). The phenomenon likely because DHS is located in one of the center of rapid economic development in China. Specifically, mean annual throughfall DIN deposition varied from $2.7 \mathrm{~kg}-\mathrm{N} \mathrm{ha} \mathrm{yr}^{-1}$ to $33.0 \mathrm{~kg}-\mathrm{N} \mathrm{ha} \mathrm{yr}^{-1}$, with an average of $10.6 \mathrm{~kg}-\mathrm{N} \mathrm{ha} \mathrm{yr}^{-1}$. Throughfall $\mathrm{N}-\mathrm{NO}_{3}^{-}$ deposition varied from $0.9 \mathrm{~kg}-\mathrm{N} \mathrm{ha}{ }^{-1} \mathrm{yr}^{-1}$ to $11.0 \mathrm{~kg}-\mathrm{N} \mathrm{ha}{ }^{-1} \mathrm{yr}^{-1}$, and throughfall $\mathrm{N}-\mathrm{NH}_{4}^{+}$ranged from $1.9 \mathrm{~kg}-\mathrm{N} \mathrm{ha} \mathrm{yr}^{-1}$ to $22.0 \mathrm{~kg}-\mathrm{N} \mathrm{ha} \mathrm{hr}^{-1} \mathrm{yr}^{-1}$. Mean annual bulk DIN deposition ranged from $4.1 \mathrm{~kg}-\mathrm{N} \mathrm{ha}{ }^{-1} \mathrm{yr}^{-1}$ to $25.4 \mathrm{~kg}-\mathrm{N} \mathrm{ha}^{-1} \mathrm{yr}^{-1}$, with $32 \%$ in the form of $\mathrm{N}-\mathrm{NO}_{3}^{-}\left(3.1 \mathrm{~kg}-\mathrm{N} \mathrm{ha}{ }^{-1} \mathrm{yr}^{-1}\right)$, whereas the remaining $68 \%$ was $\mathrm{N}-$ $\mathrm{NH}_{4}^{+}$(6.7 kg-N ha ${ }^{-1} \mathrm{yr}^{-1}$ ) (Fig. 2a). DIN deposition in precipitation in our study was, on average, $9.8 \mathrm{~kg}-\mathrm{N} \mathrm{ha} \mathrm{yr}^{-1} \mathrm{yr}^{-1}$, which was higher than that measured in the United States (3.0 kg-N ha ${ }^{-1} \mathrm{yr}^{-1}$ ) (Holland, 2005), lower than the average value found in Europe in 2000 (12.1 kg-N ha ${ }^{-1} \mathrm{yr}^{-1}$ ) (De Vries et al., 2014), but compared well with the deposition level of forest ecosystems in east Asia (9.6 kg-N ha ${ }^{-1} \mathrm{yr}^{-1}$ ) (EANET, 2009). The available evidence suggests that the critical load $(\mathrm{CL})$ of $\mathrm{N}$ deposition that affects the understory biodiversity may be as low as $10-15 \mathrm{~kg}^{-\mathrm{N} \mathrm{ha}}{ }^{-1} \mathrm{yr}^{-1}$ (Bobbink et al., 2010). When deposited $\mathrm{N}$ is above the CL, forest ecosystems are more susceptible to frost, drought, pathogens and pests (De Vries et al., 2007). Consequently, we speculate that forest ecosystems, particularly forest ecosystems in the southern part of the NSTEC and its vicinity, may be predisposed to be affected by these ecological stresses.

Generally, $\mathrm{N}-\mathrm{NO}_{3}^{-}$primarily derived from the combustion of fossil fuels; whereas the main anthropogenic sources of $\mathrm{N}-\mathrm{NH}_{4}^{+}$ include human and animal excrement, the volatilization of fertilizer, and biomass burning, which are closely related with agricultural activities (Hertel et al., 2006; Pineda Rojas and Venegas, 2010). Therefore, $\mathrm{N}-\mathrm{NO}_{3}^{-} / \mathrm{N}-\mathrm{NH}_{4}^{+}$ratio can be used as an evaluation of the degree of industrialization (Zhao et al., 2009). In Northeast China, with little industrial area and undisturbed by human activities, $\mathrm{N}-\mathrm{NO}_{3}^{-} / \mathrm{N}-\mathrm{NH}_{4}^{+}$ratio was 0.5 (Yu et al., 2011), Conversely,
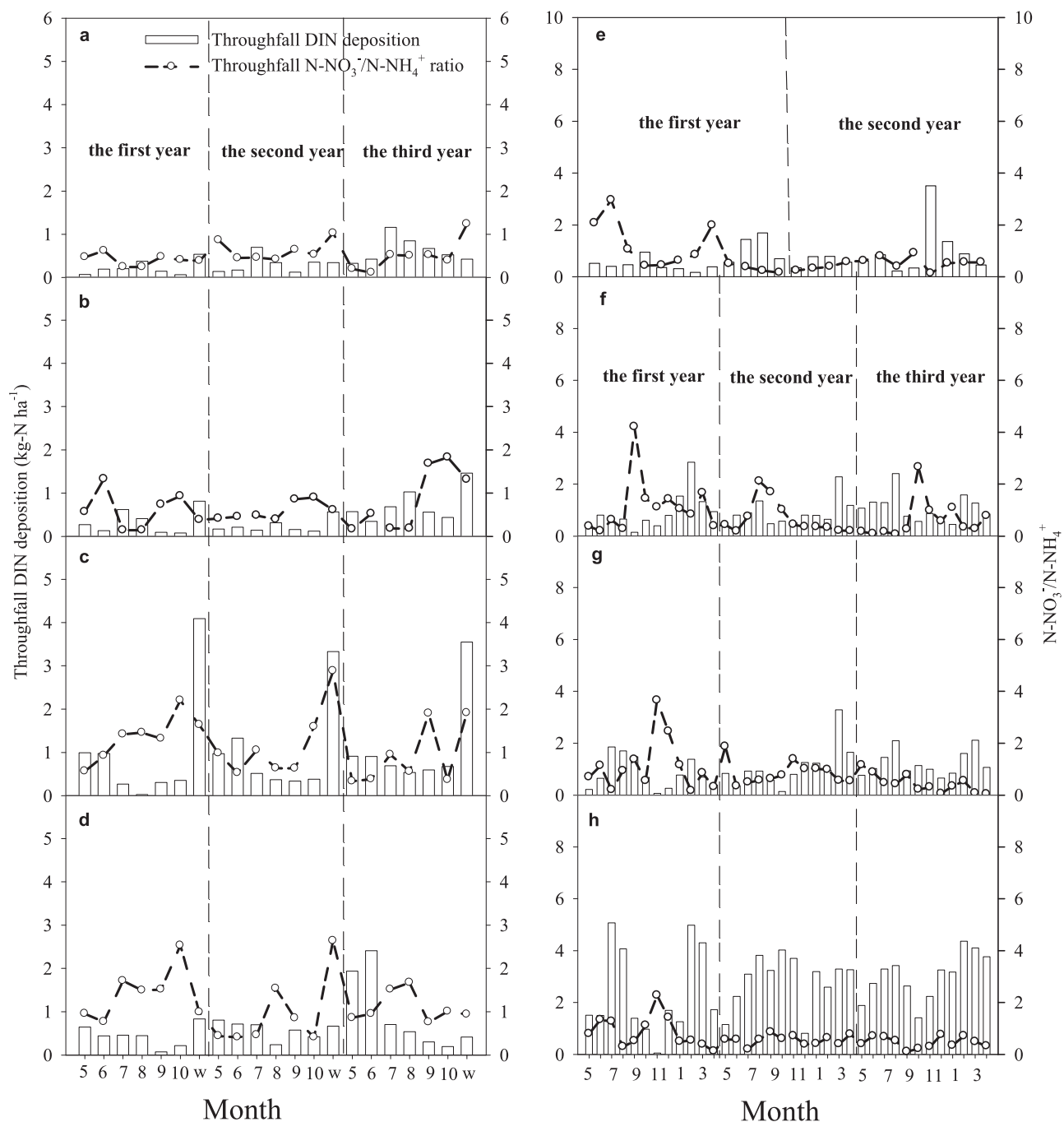

Fig. 3. Monthly distributions of throughfall dissolved inorganic nitrogen (DIN) deposition and the $\mathrm{N}-\mathrm{NO}_{3}^{-} / \mathrm{N}-\mathrm{NH}_{4}^{+}$ratio from May 2008 to April 2011 . (a) $\mathrm{HZ}$; (b) GH; (c) $\mathrm{MES}$; (d) CBS; (e) DGS; (f) HT; (g) QYZ; (h) DHS. 

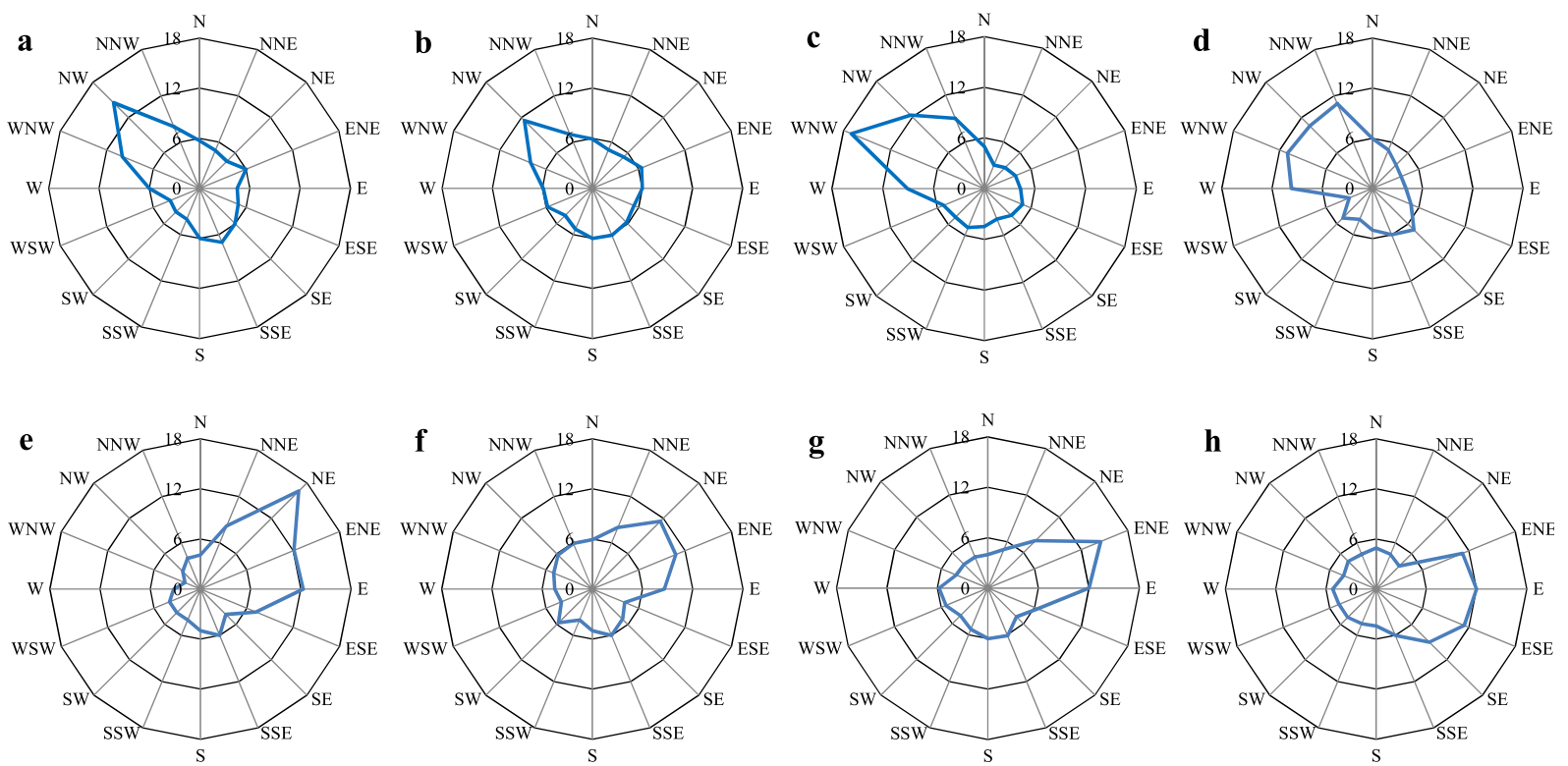

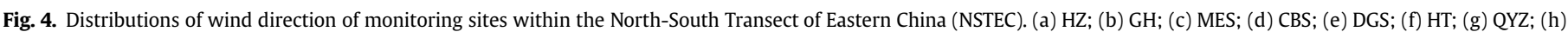
DHS.

$\mathrm{N}-\mathrm{NO}_{3}^{-} / \mathrm{N}-\mathrm{NH}_{4}^{+}$ratio was up to 1.5 in the more developed regions of the United States (Enzai et al., 2014). In our study, $\mathrm{N}-\mathrm{NO}_{3}^{-} / \mathrm{N}-\mathrm{NH}_{4}^{+}$ratio ranged from 0.4 to 1 , with an average of approximately 0.5 (Fig. 2a), suggesting that $\mathrm{N}-\mathrm{NH}_{4}^{+}$is the dominant DIN form entering the forest ecosystems. The ratio indicates that agricultural emissions, rather than industrial emissions, are the main sources of DIN deposition in this region.

Moreover, our results showed that DIN input in throughfall was higher than that in bulk deposition in the southern part of the NSTEC (Fig. 2b), pointing to the contribution of dry particles or gases attached to the leaf surface (Fenn and Poth, 2004). However, DIN deposition in precipitation is likely to be taken up by leaves through the interactions of the forest canopy, particularly in N-limited sites (Lovett and Lindberg, 1993). Therefore, throughfall DIN deposition tended to be lower than bulk DIN deposition in the northern part of the NSTEC (Fig. 2b). Hence, the forest canopy should be given serious consideration in order to precisely confirm the changes of $\mathrm{N}$ deposition in forest ecosystems.

\subsection{Seasonal trend of throughfall DIN deposition}

Throughfall DIN deposition and bulk DIN deposition displayed similar patterns; thus, as the seasonal trend and factors influence on DIN deposition, only throughfall DIN deposition was mentioned. The seasonal trend of throughfall DIN deposition was relatively complex. However, by synthesizing the three-year data, we could still determine the general fluctuation pattern. Throughfall DIN deposition in $\mathrm{HZ}, \mathrm{GH}, \mathrm{MES}$, and CBS exhibited a single peak curve during a year's observation (Fig. 3a-d). Throughfall DIN deposition in $\mathrm{HZ}$ and $\mathrm{GH}$ showed a peak that occurred in the middle of the growing season (Fig. 3a and b). In the two forest sites, the prevailing wind direction was northwest, with the exception of southeast in summer (Fig. 4a and b). However, these two sites lie in remote mountain areas that were not subjected to human disturbances. Thus, the high throughfall DIN deposition in summer might be caused mainly by emissions from natural sources, e.g., the decomposition of soil microbes, plants residues and wild animal excreta (Ludwig et al., 2001). More speculatively, high lightning frequency and sun radiation in summer could favor the increase of throughfall DIN deposition (Hastings et al., 2003). On the contrary, throughfall DIN deposition in MES and CBS was high in the beginning of the growing season (Fig. $3 c$ and $d$ ), which might be the result of agriculture activities nearby the crop fields. Generally, spring wheat was planted with ground fertilizer at the beginning of the growing season and was top-dressed about a month later. The trends were also found in Beijing, and the phenomenon was attributed $\mathrm{NH}_{3}$ volatilization induced by the application of $\mathrm{N}$ fertilizer (Liu et al., 2006). Further, soil freeze/thaw cycles could also promote throughfall DIN deposition in early spring (Edwards and Killham, 1986). Additionally, the heavy throughfall DIN deposition was also observed in winter in MES, when no fertilizer was applied in the nearby farmlands (Fig. 3c). Aneja et al. (2001) and Krupa (2003) both note that $\mathrm{NH}_{4}^{+}$aerosol (with a lifetime of 1-15 days), is a regional scale problem, and $\mathrm{NO}_{\mathrm{X}}$ has a relative longer transportation distance than $\mathrm{NH}_{3}$. The prevailing wind was westnorthwest in MES (Fig. 4c). Therefore, the high throughfall DIN deposition might be ascribed to $\mathrm{N}$ emissions by fossil-fuel combustion for winter heating in Harbin, which is approximately $100 \mathrm{~km}$ upwind of the study site.

As for forest ecosystems in the southern part of the transect, double peaks were found in a year's observation, which emerged in early spring and in middle summer, respectively (Fig. $3 \mathrm{e}-\mathrm{h}$ ). The first peak in early spring might correlate with the fact that the study sites were embraced by spring rice fields. The second peak was likely due to the large amount of $\mathrm{N}$ emissions caused by agricultural activities of summer rice, also the high rate of organic decomposition and the $\mathrm{N}$ cycle. For example, high temperature in summer could stimulate the activities of soil microbes and further hasten the decomposition and mineralization of the soil organic matter, which then increase $\mathrm{N}$ emissions (Ludwig et al., 2001). Moreover, other meteorological factors (i.e., lightning, sun radiation) could also contribute to high throughfall DIN deposition in the middle of summer (Hastings et al., 2003). Throughfall DIN deposition in DHS remained at a higher level than those in any other sites (Fig. $3 \mathrm{~h}$ ). The prevailing wind was east-northeast to east-southeast (Fig. 4h), thus the high throughfall DIN deposition in DHS might be attributed to $\mathrm{N}$ dispersion from both agriculture activities and 

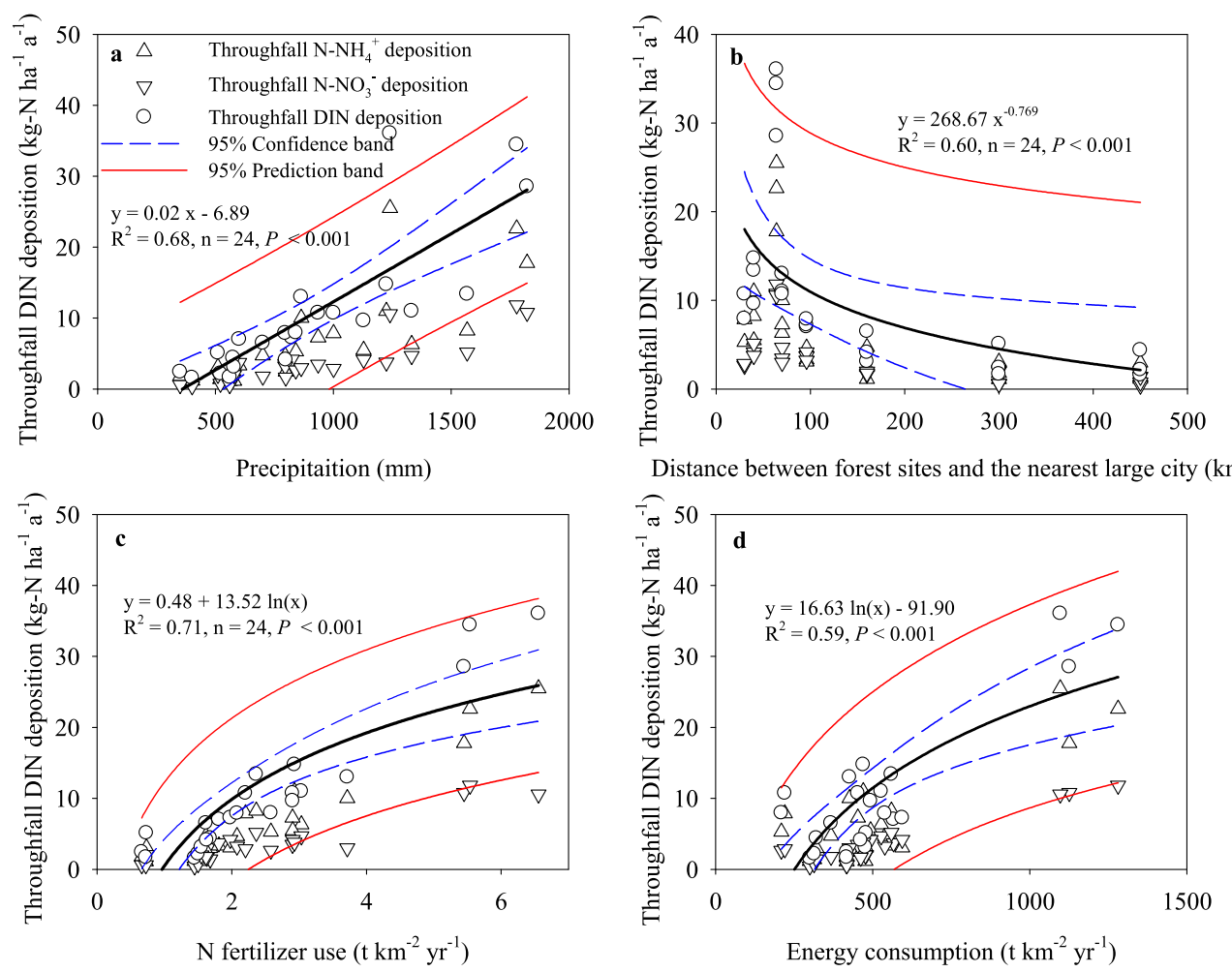

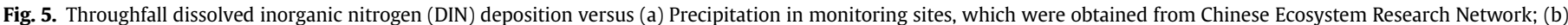

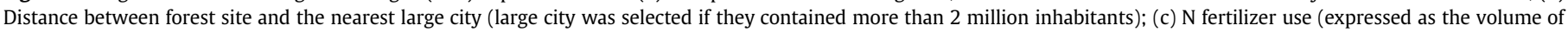

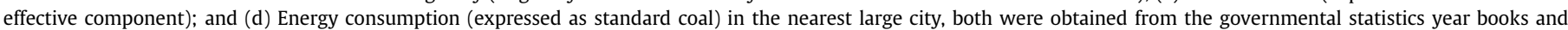
bulletins.

Full model for throughfall DIN deposition: $84.3(\%)$

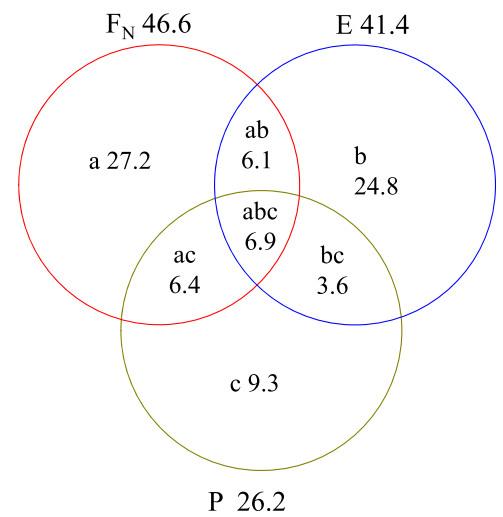

Fig. 6. Variation partitioning $\left(R^{2}\right)$ of the independent effects of $N$ fertilizer use $\left(F_{N}\right)$, energy consumption $(E)$, precipitation $(P)$, and their interactions in accounting for the variation in throughfall dissolved inorganic nitrogen (DIN) deposition. The symbols a, $\mathrm{b}, \mathrm{c}$ represented the independent effects of $\mathrm{F}_{\mathrm{N}}, \mathrm{E}$, and $\mathrm{P}$, respectively; $a b$, the interactive effect of $F_{N}$ and $E ; a c$, the interactive effect of $F_{N}$ and $P$; bc, the interactive effect of $E$ and $P$; and abc, the interactive effect of $F_{N}, E$, and P. Full model involved all of the three factors.

industrialization in Guangzhou, which is located $64 \mathrm{~km}$ east of DHS. The plausibility of the above scenario should be approved in further studies using a variety of approaches, i.e., stable $\mathrm{N}$ isotope.

\subsection{Factors influencing throughfall DIN deposition}

In our study, throughfall DIN deposition increased linearly with precipitation $\left(\mathrm{R}^{2}=0.68, P<0.001\right)$ (Fig. 5a), suggesting that
Table 2

Correlation matrix of independent variables.

\begin{tabular}{llll}
\hline Variables & $\mathrm{P}$ & $\mathrm{F}_{\mathrm{N}}$ & $\mathrm{E}$ \\
\hline $\mathrm{P}$ & 1 & $0.80^{* *}$ & $0.71^{* *}$ \\
$\mathrm{~F}_{\mathrm{N}}$ & & 1 & $0.80^{* *}$ \\
$\mathrm{E}$ & & & 1 \\
\hline
\end{tabular}

P, precipitation (mm); $\mathrm{F}_{\mathrm{N}}, \mathrm{N}$ fertilizer use $\left(\mathrm{t} \mathrm{km}^{-2} \mathrm{yr}^{-1}\right) ; \mathrm{E}$, energy consumption ( $\mathrm{t}$ $\left.\mathrm{km}^{-2} \mathrm{yr}^{-1}\right) ;{ }^{* *}, P<0.01$.

precipitation is an important driver of DIN deposition in forest ecosystems within the NSTEC. This finding was consistent with results from previous studies (Anatolaki and Tsitouridou, 2007; Kryza et al., 2012; Zhan et al., 2014). The phenomenon might be ascribed to the cleaning effect of precipitation on particles suspended in the air, which is controlled by below-cloud processes in seriously polluted areas and by in-cloud processes in marginally polluted areas (Hertel et al., 2006).

Besides precipitation, human activities are the main cause of atmospheric $\mathrm{N}$ deposition, and the pattern of $\mathrm{N}$ deposition depends mainly on N emissions (Paulot et al., 2013; Zhang et al., 2012). Cities are centers of human activities that emit a large amount of $\mathrm{N}$ pollution that subsequently influence the surrounding ecosystems through atmospheric transportation. Therefore, we documented the distance between forest sites and the nearest large city with more than 2 million inhabitants to address its relationship with throughfall DIN deposition. The result showed that throughfall DIN deposition decreased exponentially with distance $\left(R^{2}=0.60\right.$, $P<0.001$ ) (Fig. 5b). This finding was the basis for analyzing the relationship between anthropogenic $\mathrm{N}$ sources ( $\mathrm{N}$ fertilizer use and energy consumption) and throughfall DIN deposition in the ensuing analysis. Generally, we found that $\mathrm{N}$ fertilizer use and 
energy consumption were tightly related to throughfall DIN deposition, accounting for $71 \%$ and $59 \%$ of its spatial pattern, respectively (Fig. 5c and d). However, this correlation is a nonlinear (logarithmic) relationship, implying that there might be a decoupling of $\mathrm{N}$ deposition with the intensification of $\mathrm{N}$ fertilizer use and the increase of energy consumption in this region.

GLM involving $\mathrm{N}$ fertilizer use, energy consumption and precipitation could account for $84.3 \%$ variation in throughfall DIN deposition (Fig. 6). However, given the significant collinearities among the three factors (Table 2), their true roles could be obscured. In order to assess their independent and joint effects, we used partial GLM regression to examine their relative causality in the control of the spatial pattern in throughfall DIN deposition. The results showed that $\mathrm{N}$ fertilizer use, energy consumption and precipitation independently explained $27.2 \%, 24.8 \%$ and $9.3 \%$ of the variations in throughfall DIN deposition, respectively, and the joint effects of $\mathrm{N}$ fertilizer use and energy consumption, $\mathrm{N}$ fertilizer use and precipitation, energy consumption and precipitation, and $\mathrm{N}$ fertilizer use, energy consumption and precipitation explained $6.1 \%, 6.4 \%, 3.6 \%$ and $6.9 \%$, respectively (Fig. 6). The findings above indicate that anthropogenic $\mathrm{N}$ sources play a more important role than precipitation in the increase of DIN deposition. Previous studies also have suggested that anthropogenic $\mathrm{N}$ emissions now make the dominant contribution to $\mathrm{N}$ deposition in many regions (Paulot et al., 2013; Schlesinger, 2009). Zhang et al. (2012) reported that anthropogenic and natural $\mathrm{N}$ sources account for $84 \%$ and $16 \%$ of $\mathrm{N}$ deposition in the USA, respectively. An approach using $\delta^{15} \mathrm{~N}$ values revealed that $\mathrm{N}$ deposition was significant affected by industrial activities in the Athabasca oil sands region (Proemse et al., 2013). These findings are valuable to planners and decision-makers in their attempts to search for suitable strategies for $\mathrm{N}$ pollution abatement, and to evaluate the effects of consequent $\mathrm{N}$ deposition on forest ecosystems.

\subsection{Further research and recommendations}

Atmospheric $\mathrm{N}$ deposition has received increasing attention mainly due to its deleterious effects on terrestrial and aquatic ecosystems (Bobbink et al., 2010; Bouwman et al., 2002), but similar to the majority of studies, we just monitored DIN deposition. However, dissolved organic N (DON) deposition also plays a relatively pivotal role in the $\mathrm{N}$ cycle due to its increasingly significant contribution (30\%) to total atmospheric N deposition (Cornell, 2011). In Central Japan, DON averaged 10.1 kg-N ha ${ }^{-1} \mathrm{yr}^{-1}$, which constituted 32\% of total N deposition (Ham and Tamiya., 2007). Furthermore, dry deposition could provide as much amount of $\mathrm{N}$ as wet deposition or even larger (Anatolaki and Tsitouridou, 2007). For example, dry $\mathrm{N}$ deposition averaged $9.5 \mathrm{~kg}-\mathrm{N} \mathrm{ha}{ }^{-1} \mathrm{yr}^{-1}$, which was more than twice the wet $\mathrm{N}$ deposition in Europe (Kristensen et al., 2004). Consequently, the magnitude of $\mathrm{N}$ deposition in this study could underestimate the total $\mathrm{N}$ deposition, due to the missing DON deposition and dry $\mathrm{N}$ deposition. Therefore, to develop a better understanding of the $\mathrm{N}$ deposition scenarios in Chinese forest ecosystems, additional reliable measurements and long-term monitoring of the total deposition of atmospheric $\mathrm{N}$ are urgently needed.

Our estimates still contain several uncertainties due to the inclusion of only a limited number of driving forces for $\mathrm{N}$ deposition. Firstly, only $\mathrm{N}$ fertilizer use and energy consumption were considered as anthropogenic $\mathrm{N}$ sources in our study; however, other $\mathrm{N}$ sources, such as livestock and biomass burning, may also affect $\mathrm{N}$ deposition (Grimm et al., 2008; Ramalho and Hobbs, 2012). Secondly, atmospheric $\mathrm{N}$ deposition is delivered by wet, dry and fog deposition processes. These processes might be controlled by a wide range of landscape features and meteorological elements, including the canopy type and structure, topographic exposure, and so on (Chen and Mulder, 2007). However, due to the currently unavailable data for these factors, analyses of the effects of these factors should be considered in future work. Furthermore, novel methods are urgently needed in forthcoming research to explore the sources contributing to atmospheric $\mathrm{N}$ deposition. Stable $\mathrm{N}$ isotope in precipitation could detect the sources that contributed to the atmospheric N (Elliott et al., 2007; Jia and Chen, 2009); additionally, back trajectory analysis could track the geographical location of the air mass from which the precipitation was produced (Chiwa, 2010). Hence, by integrating the two methods, we could detect the potential source of $\mathrm{N}$ in precipitation more precisely, and thus, could take more effective actions to curb $\mathrm{N}$ emissions to the atmosphere.

\section{Conclusions}

Large spatio-temporal variation of DIN deposition was found in this study. The mean annual DIN deposition, with $\mathrm{N}-\mathrm{NH}_{4}^{+}$as the dominant form, increased from north to south within the NSTEC. Considering the $\mathrm{CL}$ of $\mathrm{N}$ deposition, serious ecological perturbations in this region are expected. We also found that bulk DIN deposition was greater than throughfall DIN deposition in the northern part of the NSTEC, whereas an opposite trend was displayed in the southern part of the NSTEC. Seasonal throughfall DIN deposition showed one peak in the northern part of the NSTEC, whereas two peaks appeared when moving southwards, which might be ascribed to soil temperature, agricultural activity, fossil-fuel combustion, and so on. Additionally, precipitation, $\mathrm{N}$ fertilizer use and energy consumption were correlated with throughfall DIN deposition in different patterns. The three factors jointly explained $84.3 \%$ of the spatial variation in throughfall DIN deposition, of which $\mathrm{N}$ fertilizer use was the most important, followed by energy consumption and precipitation. The findings suggest that precipitation affects DIN deposition mainly through working anthropogenic $\mathrm{N}$ sources rather than via itself. Furthermore, in order to clarify the sources of DIN deposition in forest ecosystems, novel methods are urgently required in further studies.

\section{Acknowledgments}

This work was financially supported by the National Natural Science Foundation of China (31290221, 31420103917), National Key Research and Development Program (2010CB833504), the CAS strategic Priority Research Program (XDA05050601). The authors would like to thank all related staffs of ChinaFLUX for their contribution to field work. Deep appreciation goes to anonymous reviewers for presenting valuable suggestions to improve this paper.

\section{References}

Anatolaki, C., Tsitouridou, R., 2007. Atmospheric deposition of nitrogen, sulfur and chloride in Thessaloniki, Greece. Atmos. Res. 85, 413-428.

Aneja, V.P., Roelle, P.A., Muray, G.C., Southerland, J., Erisman, J.W., Fowler, D., Asman, W.A.H., Patni, N., 2001. Atmospheric nitrogen compounds II. Emissions, transport, transformation, deposition and assessment. Atmos. Environ. 35, 1903-1911.

Bobbink, R., Hicks, K., Galloway, J., Spranger, T., Alkemade, R., Ashmore, M., Bustamante, M., Cinderby, S., Davidson, E., Dentener, F., Emmett, B., Erisman, J.W., Fenn, M., Gilliam, F., Nordin, A., Pardo, L., De Vries, W., 2010. Global assessment of nitrogen deposition effects on terrestrial plant diversity: a synthesis. Ecol. Appl. 20, 30-59.

Bouwman, A.F., Boumans, L.J.M., Batjes, N.H., 2002. Estimation of global $\mathrm{NH}_{3}$ volatilization loss from synthetic fertilizers and animal manure applied to arable lands and grasslands. Glob. Biogeochem. Cycles 16, 8-1-8-14.

Chen, X.Y., Mulder, J., 2007. Atmospheric deposition of nitrogen at five subtropical forested sites in south China. Sci. Total Environ. 378, 317-330.

Chiwa, M., 2010. Characteristics of atmospheric nitrogen and sulfur containing 
compounds in an inland suburban-forested site in northern Kyushu, western Japan. Atmos. Res. 96, 531-543.

Churkina, G., Brovkin, V., von Bloh, W., Trusilova, K., Jung, M., Dentener, F., 2009. Synergy of rising nitrogen depositions and atmospheric $\mathrm{CO}_{2}$ on land carbon uptake moderately offsets global warming. Glob. Biogeochem. Cycles 23, GB4027.

Cornell, S.E., 2011. Atmospheric nitrogen deposition: revisiting the question of the importance of the organic component. Environ. Pollut. 159, 2214-2222.

De Vries, W., Dobbertin, M.H., Solberg, S., Van Dobben, H.F., Schaub, M., 2014. Impacts of acid deposition, ozone exposure and weather conditions on forest ecosystems in Europe: an overview. Plant Soil 380, 1-45.

De Vries, W., Kros, H., Reinds, G.J., Wamelink, W., Mol, J., Van Dobben, H., Bobbink, R., Emmett, B., Smart, S., Evans, C., 2007. Developments in Deriving Critical Limits and Modeling Critical Loads of Nitrogen for Terrestrial Ecosystems in Europe. Alterra Rapport 1382. Alterra, Wageningen.

EANET, 2009. Acid Deposition Monitoring Network in East Asia (EANET): Data Report 2008. http://www.eanet.cc/product/index.html.

Edwards, A.C., Killham, K., 1986. The effect of freeze thaw on gaseous nitrogen loss from upland soils. Soil Use Manag. 2, 86-91.

Elliott, E.M., Kendall, C., Wankel, S.D., Burns, D.A., Boyer, E.W., Harlin, K., Bain, D.J., Butler, T.J., 2007. Nitrogen isotopes as indicators of $\mathrm{NO}_{\mathrm{x}}$ source contributions to atmospheric nitrate deposition across the Midwestern and Northeastern United States. Environ. Sci. Technol. 41, 7661-7667.

Enzai, D., De Vries, W., Galloway, J.N., Hu, X.Y., Fang, J.Y., 2014. Changes in wet nitrogen deposition in the United States between 1985 and 2012. Environ. Res. Lett. 9, 095004 (8pp).

Fang, Y.T., Gundersen, P., Vogt, R.D., Koba, K., Chen, F.S., Chen, X.Y., Yoh, M., 2011. Atmospheric deposition and leaching of nitrogen in Chinese forest ecosystems. J. For. Res. 16, 341-350.

Fenn, M.E., Poth, M.A., 2004. Monitoring nitrogen deposition in throughfall using ion exchange resin columns: a field test in the San Bernardino Mountains. J. Environ. Qual. 33, 2007-2014.

Fischer, R., Mues, V., Ulrich, E., Becher, G., Lorenz, M., 2007. Monitoring of atmospheric deposition in European forests and an overview on its implication on forest condition. Appl. Geochem. 22, 1129-1139.

Galloway, J.N., Townsen, A.R., Erisman, J.W., Bekunda, M., Cai, Z.C., Freney, J.R., Martinelli, L.A., Seitzinger, S.P., Sutton, M.A., 2008. Transformation of the nitrogen cycle: recent trends, questions and potential solutions. Science 320, 889-892.

Grimm, N.B., Foster, D., Groffman, P., Grove, J.M., Hopkinson, C.S., Nadelhoffer, K.J. Pataki, D.E. Peters, D.P. 2008. The changing landscape: ecosystem responses to urbanization and pollution across climatic and societal gradients. Front. Ecol. Environ. 6, 264-272.

Ham, Y.S., Tamiya, S., 2007. Contribution of dissolved organic nitrogen deposition to total dissolved nitrogen deposition under intensive agricultural activities. Water Air Soil Pollut. 178, 5-13.

Hastings, M.G., Sigman, D.M., Lipschultz, F., 2003. Isotopic evidence for source changes of nitrate in rain at Bermuda. J. Geophys. Res. 108, D240.

Heikkinen, R.K., Luoto, M., Kuussaari, M., Pöyry, J., 2005. New insights into butterflyenvironment relationships using partitioning methods. Proc. R. Soc. 272, 2203-2210.

Hertel, O., Skjoth, C.A., Lofstrom, P., Geels, C., Frohn, L.M., Ellermann, T., Madsen, P.V., 2006. Modeling nitrogen deposition on a local scale-a review of the current state of the art. Environ. Chem. 3, 317-337.

Holland, E.A., Braswell, B.H., Sulzman, J., Lamarque, J.F., 2005. Nitrogen deposition onto the United States and Western Europe: synthesis of observation and models. Ecol. Appl. 15, 38-57.

Jia, G.D., Chen, F.J., 2009. Monthly variations in nitrogen isotopes of ammonium and nitrate in wet deposition at Guangzhou, south China. Atmos. Environ. 44, 2309-2315.

Kristensen, H.L., Gundersen, P., Callesen, I., Reinds, G.J., 2004. Throughfall nitrogen deposition has different impacts on soil solution nitrate concentration in
European coniferous and deciduous forests. Ecosystems 7, 180-192.

Krupa, S.V., 2003. Effects of atmospheric ammonia $\left(\mathrm{NH}_{3}\right)$ on terrestrial vegetation: a review. Environ. Pollut. 124, 179-221.

Kryza, M., Werner, M., Dore, A.J., Blas, M., Sobik, M., 2012. The role of annual circulation and precipitation on national scale deposition of atmospheric sulphur and nitrogen compounds. J. Environ. Manag. 109, 70-79.

Liu, X.J., Ju, X.T., Zhang, Y., He, C., Kopsch, J., Fusuo, Z., 2006. Nitrogen deposition in agroecosystems in the Beijing area. Agric. Ecosyst. Environ. 113, 370-377.

Lovett, G.M., Lindberg, S.E., 1993. Atmospheric deposition and canopy interactions of nitrogen in forests. Can. J. For. Res. 23, 1603-1616.

Ludwig, J., Meixner, F.X., Vogle, B., Förstner, J., 2001. Soil-air exchange of nitric oxide: an overview of processes, environmental factors, and modeling studies. Biogeochemistry 52, 225-257.

National Bureau of Statistics of China, 2009-2011. China Statistical Yearbook. China Statistics Press.

Nave, L.E., Vance, E.D., Swanston, C.W., Curtis, P.S., 2009. Impacts of elevated N inputs on north temperate forest soil $\mathrm{C}$ storage, $\mathrm{C} / \mathrm{N}$, and net $\mathrm{N}$-mineralization. Geoderma 153, 231-240.

Paulot, F., Jacob, D.J., Henze, D.K., 2013. Sources and processes contributing to nitrogen deposition: an adjoint model analysis applied to biodiversity hotspots worldwide. Environ. Sci. Technol. 47, 3226-3233.

Peng, S.L., Zhao, P., Ren, H., 2002. The possible heat-driven pattern variation of zonal vegetation and agricultural ecosystem, along the North-South transect of China under the global change. Earth Sci. Front. 9, 218-226 (in Chinese).

Pineda Rojas, A.L., Venegas, L.E., 2010. Interannual variability of estimated monthly nitrogen deposition to coastal waters due to variations of atmospheric variables model input. Atmos. Res. 96, 88-102.

Proemse, B.C., Mayera, B., Fennb, M.E., Rossb, C.S., 2013. A multi-isotope approach for estimating industrial contributions to atmospheric nitrogen deposition in the Athabasca oil sands region in Alberta, Canada. Environ. Pollut. 182, 80-91.

Ramalho, C.E., Hobbs, R.J., 2012. Time for a change: dynamic urban ecology. Trends Ecol. Evol. 27, 179-188.

Richter, A., Burrows, J.P., Nuss, H., Granier, C., Niemeier, U., 2005. Increase in tropospheric nitrogen dioxide over China observed from space. Nature 437, 129-132.

Schlesinger, W.H., 2009. On the fate of anthropogenic nitrogen. Proc. Natl. Acad. Sci. U. S. A. 106, 203-208.

Sheng, W.P., Yu, G.R., Jiang, C.M., Yan, J.H., Liu, Y.F., Wang, S.L., Wang, B., Zhang, J.H., Wang, C.K., Zhou, M., Jia, B.R., 2013. Monitoring nitrogen deposition in typical forest ecosystems along a large transect in China. Environ. Monit. Assess. 185, 833-844.

Sutton, M.A., Oenema, O., Erisman, J.W., Leip, A., Van Grinsven, H., Winiwarter, W., 2011. Too much of a good thing. Nature 472, 159-161.

Thomas, R.Q., Canham, C.D., Weathers, K.C., Goodale, C.L., 2010. Increased tree carbon storage in response to nitrogen deposition in the US. Nat. Geosci. 3, $13-17$.

Walna, B., Kurzyca, I., 2007. Evaluation of bulk deposition in protected woodland area in Western Poland. Environ. Monit. Assess. 131, 13-26.

Yu, W.T., Jiang, C.M., Ma, Q., Xu, Y.G., Zou, H., Zhang, S.C., 2011. Observation of the nitrogen deposition in the lower Liaohe River Plain, Northeast China and assessing its ecological risk. Atmos. Res. 101, 460-468.

Zhan, X.Y., Yu, G.R., He, N.P., Fang, H.J., Jia, B.R., Zhou, M., Wang, C.K., Zhang, J.H. Zhao, G.D., Wang, S.L., Liu, Y.F., Yan, J.H., 2014. Nitrogen deposition and its spatial pattern along the North-South Transect of Eastern China. Chin. Geogr. Sci. 24, 137-146.

Zhang, Y., Song, L., Liu, X.J., Li, W.Q., Lu, S.H., Zheng, L.X., Bai, Z.C., Cai, G.Y, Zhang, F.S., 2012. Atmospheric organic nitrogen deposition in China. Atmos. Environ. 46, 195-204.

Zhao, X., Yan, X.Y., Xiong, Z.Q., Xie, Y.X., Xing, G.X., Shi, S.L., Zhu, Z.L., 2009. Spatial and temporal variation of inorganic nitrogen wet deposition to the Yangtze River Delta Region, China. Water, Air, Soil Pollut. 203, 277-289. 